\title{
La identidad como respuesta: un acercamiento retórico-argumentativo a Rusticatio mexicana de Rafael Landivar
}

\author{
Joaquín Rodríguez Beltrán
}

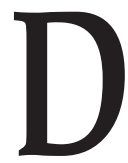

os de las ideas más repetidas en torno a Rusticatio mexicana de Rafael Landívar son, por una parte, que lo que determina la obra es una nostalgia provocada por el exilio en que se encontraba el autor al momento de escribirla y, por otra parte, que el aspecto más significativo es lo que podría llamarse "exaltación patriota del suelo novohispano". Sin tratar de desmentir tales interpretaciones, lo que se pretende defender aquí es que la obra tiene en sí misma la posibilidad de ser comprendida mediante otro aspecto determinante: su inserción en el debate que Antonello Gerbi ${ }^{1}$ ha llamado la disputa del Nuevo Mundo.

Si se acepta la idea de que todo texto quiere dar algo a conocer, sea cual fuere la índole de ello, se concluirá fácilmente que una obra cuyo rasgo más evidente sea la descripción de algo, tendrá por objeto principal mostrarlo a un público. Ahora bien, cuando sobre un tema ya se ha escrito de manera extensa, la aparición de un texto nuevo se justifica porque pretende aportar algo novedoso al respecto, lo cual adquiere sentido al contrastarlo con lo ya dicho. Rusticatio mexicana, que se centra en describir la naturaleza y diversas actividades humanas de la Nueva España, surge como parte de una larga tradición volcada al ensalzamiento de la naturaleza americana. La obra, en tanto que escrita por un jesuita criollo novohispano exiliado en una Europa que acababa de renovar su visión acerca de América, puede comprenderse como un intento por mostrar su propio punto de vista, como una respuesta. Hagamos primeramente una descripción somera de esa nueva visión y, posteriormente, de los puntos principales de tal contestación.

Es bien conocida la crítica que emprendió Clavijero en su Historia antigua de México en contra de un grupo de intelectuales europeos que, a grandes

${ }^{1}$ Antonello Gerbi, La disputa del Nuevo Mundo. Historia de una polémica, 17501900. México, FCE, 1982. 
rasgos, habían llegado a la idea - no nueva- de la inferioridad de América mediante métodos -novedosos- que, tomando como base una visión diacrónica de la humanidad, consistían en un esfuerzo racional por explicar los distintos estadios de civilización del hombre a partir de fenómenos naturales.

Con todo, y no obstante la radical revisión a que sometía Hume, la secular doctrina de la conexión entre clima y caracteres -readaptada a las nuevas circunstancias, robustecida con el ansia racionalista de relaciones claras, precisas, no variables en el curso de los tiempos, sino fijas como las leyes de la naturaleza, esquemática, evidente, sencilla e irrefutable como lo caliente y lo frío, la sequía y los aguaceros-acababa por confluir en el juicio sumario que Europa estaba a punto de pronunciar sobre América. El continente que en el siglo XVI había suscitado tantos problemas filosóficos y teológicos, cosmográficos y políticos, ahora, tras el eclipse de la era barroca, se representaba como naturaleza y como clima a los espíritus prácticos y apasionados del siglo XVIII. ${ }^{2}$

Es claro, entonces, lo que une a este grupo de intelectuales europeos, entre cuyos nombres normalmente se menciona al naturalista Buffon, al "philosophe" Cornelius de Pauw y al historiador William Robertson, son dos cosas: el apelar al "método" como una de las mayores justificaciones para sus trabajos, y el basarse en el determinismo climático para validar sus juicios acerca del grado de civilización o barbarie de diversos grupos humanos. Las observaciones de Buffon, o mejor dicho, las que recopiló a partir de viajeros "fidedignos", pueden ser vistas como el punto de partida de muchas ideas posteriores. Hay cuatro observaciones que tendrían grandes repercusiones: primero, que en el Nuevo Mundo los mamíferos son más pequeños, menos variados y menos fuertes -el tapir es diminuto en comparación con el elefante; el jaguar, lampiño, no iguala en fuerza al león, tan potente y melenudo-; segundo, que los animales domésticos traídos de Europa a América sufren de cierta degeneración o decadencia -el ganado bovino y los caballos pierden fuerza en el suelo americano-; tercero, que el Nuevo Mundo, en comparación con el Viejo, tiene numerosos manglares y zonas pantanosas de gran humedad; y cuarto, que América posee insectos y reptiles más variados y de mayor tamaño.

Esto, dentro del sistema de Buffon, el cual propone que en un inicio la tierra estuvo cubierta de agua, lleva a plantear el estado bruto de la naturaleza americana, es decir, su carácter nuevo y poco desarrollado. Pues si es hostil al crecimiento de los animales superiores y al mismo tiempo favorece con su

${ }^{2}$ Ibid., p. 55. 
clima a los seres inferiores como batracios, reptiles, culebras e insectos, que tienen -según él- "sangre de agua" y por tanto se reproducen y desarrollan mejor en un medio húmedo hasta adquirir algunos proporciones "gigantescas", entonces se trata de un mundo primigenio "que permaneció durante más tiempo bajo las aguas del mar, que está recién salido de ellas y aún no se ha secado bien". 3

El caso de Cornelius de Pauw presenta notables diferencias en relación con Buffon. Para este último, la inferioridad del indio se deriva de su visión de la naturaleza americana; para el primero, en cambio, el centro de gravitación pasa de la naturaleza al hombre americano. ${ }^{4}$ Buffon habla de hombres primitivos y de naturaleza en estado bruto, en la infancia, al referirse por ejemplo a las tribus del Amazonas; De Pauw se refiere a un estado viciado, depravado, algo que fue en retroceso.

William Robertson, por su parte, tomó un tono menos polémico que De Pauw y estuvo más abierto ante las fuentes históricas españolas. No obstante esta diferencia, Robertson retrata en su Historia de América la naturaleza y

${ }^{3}$ Ibid., pp. 20-21. Lo cierto es que, contra lo que parece decir Gerbi, el juicio de Buffon no se aplica en general a todo el continente americano. Pero son sin duda las observaciones de este naturalista las que, al generalizarse de manera indiscriminada a todo el continente, y al unirse a su sistema, pueden llevar a tal conclusión. Cuando Buffon aborda el asunto de manera directa, menciona que algunas zonas de América son más antiguas y otras más nuevas. Por ejemplo, afirma lo siguiente al referirse a las líneas más largas que se pueden trazar al medir todo un continente, América de norte a sur y el bloque eurasiático-africano de este a oeste (África hasta China) y de norte a sur (norte de Europa hasta el sur de África): "Les pays les plus anciens doivent être les plus voisines de ces lignes, et en même temps les plus élevés, et [...] les terres les plus nouvelles en doivent être les plus éloignées, et en même temps les plus basses. Ainsi en Amérique la terre des Amazones, la Guiane et le Canada seront les parties plus nouvelles; en jetant les yeux sur la carte de ces pays, on voit que les eaux y sont répandues de tous côtés, qu'il a un grand nombre de lacs et de très-grands fleuves, ce qui indique encore que ces terres sont nouvelles au contraire le Tucuman, le Pérou et le Mexique sont des pays très-élevés, fort montueux, et voisins de la ligne qui partage le continent" (Georges Louis Leclerc Buffon, Histoire naturelle, générale et particulière. París, Imprimerie Royal, 1749, t. 1, pp. 209-210).

${ }^{4}$ Además de aquello en lo que se enfocan estos dos autores, otra diferencia crucial es la intención de sus obras. En el caso de De Pauw, se percibe desde el inicio de su obra que para él hablar de los americanos es más un pretexto que un objetivo en sí mismo, un pretexto en buena medida para criticar ciertos comportamientos de los europeos: "Si ceux qui prêchent la vertu chez les nations policées, sont trop vicieux euxmêmes, pour instruire des Sauvages sans les tyranniser, laissons végéter ces sauvages en paix, plaignons-les, si leurs maux surpassent les nôtres, et si nous ne pouvons contribuer à leur bonheur, n'augmentons pas leurs misères" (Cornelius de Pauw, Recherches philosophiques sur les Américains, ou mémoire intéressant pour servir l'Histoire de l'Espèce Humaine. Londres, 1774, t. 1, p. v). 
al hombre americano en términos emparentados a los anteriores: respecto a ésta, resalta el predominio del frío en el continente americano; respecto al hombre, plantea un esquema donde deja relativamente mal paradas a las que se consideraban las grandes civilizaciones americanas. En efecto, en Robertson queda muy clara una de las tendencias que, siguiendo a Cañizares Esguerra, ${ }^{5}$ regían los trabajos de la época: ante la desconfianza que les generaban numerosas fuentes históricas a estos intelectuales -especialmente las elaboradas a partir de escritura no alfabética y las que provenían de españoles impregnados de "fanatismo religioso"- el mejor modo de estudiar el desarrollo del hombre "objetivamente" era buscar directamente culturas que, por sus características, demostraran en aquellos momentos estar en estadios más primitivos de la humanidad; una tendencia que, por lo demás, podríamos remontar hasta Tucídides. ${ }^{6}$ Dentro de esta perspectiva, el Nuevo Mundo se presentaba como una gran oportunidad para descubrir al hombre en etapas anteriores dentro de la escala evolutiva en cuyo pináculo se colocaba, evidentemente, Europa. Así, en el esquema de tres niveles que defendía Robertson -donde el salvajismo tiene el lugar más bajo; la barbarie, el intermedio, y la civilización, el más alto- los mexicas y los incas ocupaban el segundo nivel, dejando a las otras poblaciones americanas en el salvajismo absoluto. Digno de notarse es el hecho de que uno de los aspectos centrales que hacían posible adquirir el estatus de civilización era el comercio; Robertson se adscribe en el llamado "humanismo comercial", que defendía que "el surgimiento del comercio no amenazaba las virtudes cívicas". ${ }^{7}$

Robertson también menciona algo que tendría fuertes implicaciones simbólicas; cuando describe los hermosos plumajes de las aves americanas, escribe: "But nature, satisfied with clothing them in this gay dress, has denied most of them that melody of sound, and variety of notes, which catches and delights the ear" ${ }^{8}$ Este silencio de las aves, señal de la tristeza y carácter lúgubre de la naturaleza del Nuevo Mundo, se elevó a símbolo de la impotencia expresiva americana en el ámbito de la poesía.

${ }^{5}$ Jorge Cañizares Esguerra, Cómo escribir la historia del Nuevo Mundo. Historiografías, epistemologías e identidades en el mundo del Atlántico del siglo XVIII. México, FCE, 2007, p. 87.

${ }^{6}$ Robert Nisbet, Historia de la idea del progreso. Barcelona, Gedisa, 1991, p. 49.

${ }^{7}$ J. Cañizares Esguerra, op. cit., p. 82.

8 "Pero la naturaleza, contenta con vestirlas de alegres ropajes, le negó a la mayoría de ellas la melodía de sonidos y la variedad de notas que atrapan al oído y lo deleitan" (A. Gerbi, op. cit., p. 199. Todas las traducciones son mías). 


\section{Rusticatio mexicana como una respuesta}

Antes de pasar a los resultados del análisis de Rusticatio al trasluz de todo lo anterior, es preciso hacer algunas aclaraciones. Algunos han observado 9 que no hay evidencia de que Landívar participara abiertamente en la polémica, lo cual es cierto si se entiende por "abiertamente" la mención explícita de los detractores para intentar refutarlos punto por punto, sin embargo, es clara la imposibilidad de contextualizar Rusticatio mexicana en el plano de la historia de las ideas sin el marco de la disputa del Nuevo Mundo, sin la idea de una reacción -más allá de una simple nostalgia del exilio- frente a la visión que el grupo detractor de intelectuales antes mencionado dio de América. Además, adoptar la perspectiva de que Landívar no participó en la contienda es dejar de lado totalmente una carta del mismo Landívar "en contra de las ideas extravagantes de los que negaban a los mexicanos el don de las letras humanas y las ciencias", ${ }^{10}$ que fue una de las modalidades que adquirió la idea de la inferioridad americana. Recuérdese, al respecto, que los jesuitas expulsos se enfrentaron incluso, en Italia, con algunos intelectuales incapaces de creer que fuera posible que hubiera personas que dominaran el latín en condiciones climáticas tan "adversas" y con una lengua materna que no fuera el italiano.

Por otra parte, podría parecer extraño que se pretenda colocar la Rusticatio en un plano adverso a ideas que a grandes rasgos y sin mucho rigor podrían verse como "ilustradas", que es precisamente la corriente a la que muchos suelen adscribir la obra; a este respecto, además de Graciela Nemes, ${ }^{11}$ se puede resaltar la visión de Kerson, que vincula la Rusticatio directamente con la Ilustración. De cualquier modo, existen las pruebas suficientes para creer que las descripciones que durante el siglo ilustrado se elaboraron acerca de América y, por tanto, de la Nueva España provocarían el choque necesario para plantear, al menos como una de las razones, la creación de una obra como la Rusticatio. Además, en un clima como el que vivieron los jesuitas exiliados, era imposible no estar al tanto de todas estas ideas; se sabe que Landívar leyó -pues los cita directamente en la Rusticatio- a Robertson y a Valmont de

9 Arnold L. Kerson, "The Republic of the Beavers", en Utopian Studies, vol. 11, núm. 2, 2000, p. 30.

${ }^{10}$ Manuel Ignacio Pérez Alonso, El destierro de los jesuitas mexicanos y la formación de la conciencia de la nacionalidad. México, Universidad Iberoamericana, 1987 , p. 31.

${ }^{11}$ Anthony Higgins, Constructing the criollo Archive: Subjects of Knowledge in the Bibliotheca Mexicana and the Rusticatio Mexicana. West Lafayette, Indiana, Universidad de Purdue, 2000, p. 113. 
Bomare, quien se había basado principalmente en Buffon, ${ }^{12}$ y también que estuvo en contacto con el grupo de expulsos. ${ }^{13}$

Es indiscutible, entonces, que la obra nace dentro de un contexto dialógico de discusión caracterizado principalmente por una intención de mostrar a un grupo intelectual europeo todo lo relativo a la América española, la cual, al atravesar uno de sus mejores momentos en términos económicos, ponía en evidencia su propia riqueza natural en provecho del orgullo criollo.

\section{Lo singular como una lucha por lo universal: la argumentación en Rusticatio mexicana}

Con todo esto como preámbulo, he aquí los resultados del análisis de Rusticatio mexicana siguiendo el parámetro retórico-argumentativo descrito por Chaïm Perelman y Lucie Olbrechts-Tyeca. ${ }^{14}$ Nuestra tesis es que si es posible adjudicarle un carácter de réplica o de disputa a Rusticatio mexicana, entonces éste consiste en resaltar la singularidad -que engloba tanto lo favorable como lo temible- dentro del marco de una universalidad de la que estaba siendo excluida la Nueva España a través de las ideas anteriormente descritas. Lejos de ser un ensalzamiento simplista de las cualidades y las particularidades novohispanas, como una enumeración de las razones para sentirse orgullosos de la patria o como un compendio de curiosidades ante los ojos ajenos, la obra forma una estructura en cuyo pináculo se encuentra la descripción de todo lo que es admirable y en cuya base se asienta un conjunto de valores comprendidos como universales - desde el punto de vista natural, humano y religioso-, de los cuales no puede escaparse ningún sector de la naturaleza, ningún hombre, lo cual está en franca oposición a la tesis principal del grupo detractor. En cierto modo, el vértice funciona como el eje de ataque; el basamento, como el soporte. Los engranajes de tal estructura son las diversas estrategias retórico-argumentativas que mencionaremos someramente y que -cabe esperar- aclararán y demostrarán la idea anterior.

Rusticatio mexicana articula su argumentación y su intervención en el debate en torno a un auditorio específico - en terminología de Perelman-,

12 A. L. Kerson, "La Rusticatio mexicana de Rafael Landívar y la Ilustración", en Saber Novohispano. Anuario del Centro de Estudios Novohispanos, núm. 1. Zacatecas, Universidad Autónoma de Zacatecas, 1994, p. 247.

${ }^{13}$ M. I. Pérez Alonso, "El padre Rafael Landívar, S. J.", en Estudios de Historia Novohispana, núm. 6. México, UNAM, enero, 1978, p. 11.

${ }^{14}$ Chaïm Perelman y Lucie Olbrechts-Tyeca, Tratado de la argumentación: la nueva retórica. Madrid, Gredos, 1989. 
que no es más que un público europeo culto. ${ }^{15}$ Landívar lo delimita desde el inicio del Monitum:

Rusticationis Mexicanae huic carmini praefixi titulum, tum quod fere omnia in eo congesta ad agros Mexicanos spectent, tum etiam quod de Mexici nomine totam Novam Hispaniam vulgo in Europa appellari sentiam, nulla diversorum regnorum ratione habita. ${ }^{16}$

El auditorio europeo es, pues, lo suficientemente fuerte como para tener una influencia decisiva en la elección del título de la obra. Aquí, además, se percibe la conciencia de Landívar de que está ante un auditorio cuya característica principal con respecto al tema del poema es el desconocimiento o la falta de información.

\section{Primer argumento frente al auditorio europeo}

\section{La premisa}

"En la práctica argumentativa, los datos [en tanto que premisas] constituyen los elementos sobre los cuales parece existir un acuerdo considerado, al menos provisional o convencionalmente, unívoco y fuera de discusión". ${ }^{17}$ Tomando en consideración, además de lo anterior, que en la obra de Landívar es bastante notoria una necesidad de basarse en una descripción de los hechos tal como se presentan, uno podría estar tentado a decir que son éstos la premisa mediante la cual se articula la respuesta landivariana a la tesis principal del grupo detractor; sin embargo, en el caso de la disputa del Nuevo Mundo, los hechos mismos son debatidos, al menos una buena cantidad de ellos. Los

${ }^{15}$ La obra también ejerce cierta argumentación en torno a un auditorio distinto, a saber, el criollo novohispano educado, pero ello no atañe de manera directa a la argumentación que se está analizando aquí. Por otro lado, hay que advertir que auditorio no tiene nada que ver con el uso de la segunda persona del singular o plural en las invocaciones a lo largo de Rusticatio mexicana. El "interlocutor" de estas invocaciones se acerca más a la noción de narratario en teoría literaria moderna, que es un recurso textual que no está en absoluto relacionado con un auditorio (público receptor) al que se quiere persuadir.

16 "He titulado a este poema Rusticatio mexicana, no sólo porque casi todas las cosas que aparecen en él se refieren a los campos mexicanos, sino también porque percibo que la Nueva España en su conjunto es en Europa vulgarmente llamada por el nombre de México, sin tomar en cuenta sus diversos reinos" (Rafael Landívar, Rusticatio mexicana. Guatemala, Universidad Rafael Landívar, 2001, Monitum, 1).

${ }^{17}$ C. Perelman y L. Olbrechts-Tyeca, op. cit., p. 199. 
"datos" que se presentan en Rusticatio mexicana escapan a la definición aquí expuesta, puesto que muchos de éstos son novedosos para el auditorio europeo de Landívar. Llegamos, pues, a la primera premisa que se comparte con el grupo detractor, al tiempo que es la piedra angular con que se le combate: no los datos en sí mismos, sino la exigencia de precisión en ellos: el método. La objetividad en la presentación de los hechos y la búsqueda de claridad son, por tanto, objetos de común acuerdo - esto es, premisas- en la argumentación con el auditorio europeo. El aticismo, que distinguió a una buena parte de la generación de jesuitas expulsos de la Nueva España, funciona en este caso como una premisa. ${ }^{18}$ No es en vano que el primer libro de la Rusticatio inicie de este modo:

Obtegat arcanis alius sua sensa figuris, abstrusas quarum nemo penetrare latebras ausit, et ingrato mentem torquere labore; tum sensum brutis aptet, gratasque loquelas; impleat et campos armis, et funere terras, omniaque armato debellet milite regna. ${ }^{19}$

Así, desde sus inicios el poema se declara alejado del disfraz de palabras oscuras, dejando lugar a que, si no se logra expresar con claridad, es por la dificultad de hacer encajar un tema enteramente nuevo en los moldes de una lengua antigua. ${ }^{20}$ De manera significativa, a las palabras engañosas y "gratas" al oído se les atribuye una facultad específicamente persuasiva: la de cambiar los comportamientos e impulsar las guerras. Sin duda, si nuestros presupuestos se sostienen, en una renuncia explícita a la cualidad engañosa de la palabra sólo puede verse la necesidad, por parte del orador-escritor, de ganar credibilidad.

\section{El argumento}

He aquí un pasaje que puede ayudar a aclarar cómo se desarrolla la idea de la singularidad, que es la clave en este argumento:

${ }^{18}$ Juan Luis Maneiro y Manuel Fabri, Vidas de mexicanos ilustres del siglo XVIII. México, unAm, 1989, p. 170.

19 "Que alguien más oscurezca sus sentidos con figuras arcanas, cuyas cuevas inaccesibles nadie se ha atrevido a penetrar; adapte entonces para los brutos el contenido y la palabrería grata; llene de armas los campos, y de muerte las tierras; y haga guerra a todos los reinos con armado ejército" (R. Landívar, op. cit., libro I, v. 1-6).

${ }^{20}$ Ibid., Monitum, 5. 
Vos rupes, Nymphae, vos vestros pandite fontes, et patrii miranda soli reserare professi

Mexiceae maiora Deae portenta canamus. ${ }^{21}$

A juzgar por lo que se dice justo después de esto -donde se describe un manantial en Ixtlán cuya rareza consiste en que, cuando una persona se acerca para contemplarlo de cerca, interrumpe su curso y deja de manarse puede afirmar que el rasgo principal de los portentos o maravillas que canta Landívar es su carácter inexplicable, algo que simplemente acontece y que hay que descubrir y divulgar como tal. Se aprecia en todo lo anterior, por tanto, una jerarquía que se basa en lugares comunes (loci argumentorum): en primer lugar está el lugar de existencia, que resalta las cosas observables; pero entre éstas, hay unas más ponderables, las que son únicas en su género, lo cual puede verse como un lugar común de lo especial, dedicado a realzar la singularidad. Así pues, no porque algo sea inexplicable debe ser descartado; por el contrario, precisamente porque es incomprensible y porque, teniendo fuentes fidedignas, se puede confiar en su existencia, debe ser mencionado, estudiado y admirado.

La argumentación de la Rusticatio se engarza, así, con dos representantes de la "epistemología patriótica" 22 que publicaron posteriormente sus obras: el jesuita exiliado Juan de Velasco, contemporáneo de Landívar, que "reunió un catálogo de fenómenos naturales típicos del reino de Quito que a los ojos de los europeos podrían haberse interpretado como fábulas", ${ }^{23}$ y José Antonio de Alzate y Ramírez, quien "insistió en que los naturalistas debían identificar las 'curiosidades' de la tierra para desenmascarar a los constructores de sistemas europeos [..., e] hizo carrera a partir de los fenómenos naturales que contradecían las 'leyes' naturales ideadas por los naturalistas europeos". ${ }^{24}$

Muchas descripciones de Landívar, como el paso extraño de dos nubes en direcciones contrarias, ${ }^{25}$ tienen la misma perspectiva. Pero dentro de la lógica de la Rusticatio, esto es sólo un escalón para llegar a descripción de los mayores portentos: los prodigios milagrosos con carga simbólica y religiosa, entre los cuales vale destacar la cruz de Tepic del Appendix, la cruz en el lago que

21 "Y ustedes, ninfas, abran las rocas, desplieguen sus fuentes; y dedicados a exponer las maravillas del patrio suelo, cantemos mayores portentos de la diosa mexicana" (ibid., libro XII, vv. 287-289).

${ }^{22}$ Es así como Cañizares llama al conjunto de respuestas por parte de americanos a las ideas puestas en circulación por De Pauw y compañía. (J. Cañizares Esguerra, $o p$. cit., cap. 4.)

${ }^{23}$ Ibid., pp. 424-425.

${ }^{24}$ Ibid., p. 470.

${ }^{25}$ R. Landívar, op. cit., libro III, vv. 120-130. 
aparece en el libro I y el milagro del pocito de la virgen de Guadalupe. Desde la perspectiva que se presenta en la disputa del Nuevo Mundo, cuya renovación principal consistió - por parte del grupo detractor- en una secularización y racionalización del debate, lo más normal sería esperar que las posibles respuestas landivarianas estuvieran en el mismo nivel. En realidad, como se acaba de ver, sí lo están, pero no siempre, y es aquí donde surgen los prodigia de las cruces: como un argumento cuya irracionalidad (carácter inexplicable), ligada al mismo tiempo con un carácter comprobable (ahí están los portentos, presentes en la misma naturaleza, visibles para todo aquel que se atreva a dudar de ellos), le da su fuerza argumentativa. Al plantear, pues, la idea de que existen hechos inexplicables y patentes (objetivos) se instaura una especie de restricción al conocimiento, como si Landivar le impusiera al grupo detractor una barrera epistemológica más allá de la cual no pueden pasar, barrera cuyos presupuestos son evidentemente de origen católico, milagroso. Se percibe, entonces, la conclusión: respecto a la naturaleza no todo es comprensible o asequible a la mente humana, hay cosas que escapan a ella.

\section{Las estrategias retórico-argumentativas}

Los recursos retórico-argumentativos que contribuyen a este argumento, además de centrarse en apoyar la premisa (como el uso continuo de cifras exactas y unidades de medida, de imágenes explicativas y de citas textuales), tienen como función crear un continuo entre los hechos, lo digno de mención, lo admirable, lo singular y, por último, los portentos; como si se tratara de un paso obligado entre ellos. Dicho de otro modo, para el lector de la Rusticatio se presenta continuamente y de diversos modos la idea de que siempre hay un más, algo que está más allá y excede a lo anterior. Esto se hace, principalmente, mediante el contraste entre elementos con el fin de magnificar uno de ellos, lo cual puede verse como la tendencia general con la que se articula el uso de la descripción. Es éste, en efecto, el sentido de las hipérboles, muchas comparaciones, antítesis, prosopopeyas.

En el caso del libro II, del Jorullo, dicho contraste está basado en la oposición entre el antes y el después, el único de carácter temporal en la Rusticatio. Es claro en los versos 272-278. Aquí, la oposición entre una etapa de placidez previa y otra etapa de ruinas no hace sino resaltar la magnitud del evento, el ímpetu destructivo del volcán. Lo interesante es que, a partir de esta oposición, se genera un tercer elemento colocado por encima de ambos: la consecuencia a largo plazo que trajo la erupción fue una especie de purificación del aire y una mayor fertilidad de las tierras. ${ }^{26}$ Las descripciones, entonces, a través del

${ }^{26}$ Ibid., libro II, vv. 288-299. 
contraste dan la impresión de ir cuesta arriba en un ascenso casi interminable. Estos efectos retóricos, pues, al crear este ámbito donde siempre hay algo mayor, le abren paso a la presentación de los prodigios.

Asimismo, respecto al contraste, hay que mencionar que éste articula una definición específica de lo admirable, que consiste tanto en lo favorable como lo temible. En esta tendencia general a hiperbolizar, se rehuyen los puntos medios, como cuando se menciona una fuente que tiene dos características completamente opuestas: curar o apresurar la muerte ${ }^{27}$ Se intenta, pues, subrayar la singularidad. Ocurre exactamente lo mismo en el caso del volcán del Jorullo y también adquiere sentido en el libro III, de las cataratas. En efecto, éstas parecen un desarrollo o una suma de los dos temas principales anteriores, esto es, los lagos y el volcán: el agua ya se presenta (casi totalmente) como algo temible, especialmente por el ruido y fuerza de su caída.

\section{Segundo argumento frente al auditorio europeo}

\section{Las premisas}

Hay dos puntos de común acuerdo que Rusticatio mexicana comparte con las ideas del grupo detractor, puntos que se pueden considerar el origen de un argumento distinto del anterior.

En primer lugar, en toda la obra se mantiene el presupuesto del determinismo climático. Posiblemente por influencia de la larga tradición que ya existía al respecto, donde ocupaba un lugar central José de Acosta, en ningún lugar es puesto completamente en duda; más bien, se parte de dicho determinismo y, en un momento crucial, es ampliado. Esto se explicará más adelante.

La segunda premisa es un hecho en específico que tiene un papel preponderante en el conjunto de elementos descritos por Landívar: el agua. Ya se mencionó la importancia que tenía la presencia de la humedad y la abundancia de agua dentro de la visión buffoniana del mundo. Ante tal idea, uno estaría tentado a pensar que éste es al menos uno de los posibles motivos que llevarían a Landivar a dedicarle tres libros completos al agua: los lagos de México, las cataratas de Guatemala y las fuentes. De cualquier manera, lo cierto es que este mismo punto de partida para Landívar y Buffon conducen a conclusiones radicalmente distintas.

${ }^{27}$ Ibid., libro XII, vv. 179-185. 


\section{El argumento}

Siguiendo con la idea anterior, parece también significativo que la Rusticatio abra con la descripción de los lagos mexicanos, en consonancia con el orden "nestoriano" aconsejado por una larga tradición retórica, el cual consiste en colocar los argumentos más fuertes al inicio y al final de un discurso. Con este inicio, que se puede caracterizar como una argumentación ad hominem, se le da entrada al primer elemento que separa los caminos de Buffon y Landivar: la introducción de las chinampas como ejemplo. ${ }^{28}$

La generalización que crean es evidente y se verá confirmada una y otra vez a lo largo del poema: las chinampas, además de ser únicas de la laguna de México, son una muestra de la conjunción inextricable entre el agua y la fertilidad de la tierra. La humedad se presenta, pues, como el ingrediente primordial para afirmar y defender el carácter productivo de la tierra. El uso de una metagoge muestra la forma en que comienza a darse la transición -de lo particular a lo general- entre la fertilidad de las chinampas y otras áreas naturales; inmediatamente después de mencionar las esteras flotantes en "campos sonrientes de flores", ${ }^{29}$ se dice:

Has agri fluitantis opes, hunc aemula cultum proxima ripa dolet, seseque virentibus Ulmis et Cerasis, fetaque Piro, Maloque rubenti, et Lauro, et Pinu, Cedroque, et Quercubus altis, vereque certatim distinguit prata perenni. ${ }^{30}$

Pareciera que esta idea -el carácter productivo de la Nueva España- es precisamente la que permite sin dificultad la mención de los pájaros a continuación. Se podrá encontrar, así, una explicación al hecho de que, temáticamente, ocurra un adelanto - un tipo de praeparatio- y se mencionen desde aquí cosas a las que ya estaba dedicado un libro completo desde la primera edición de Rusticatio mexicana. Sin duda, también adquiere sentido que se enfatice tanto el canto de los pájaros en esta anticipación: Landívar conocía la obra de Robertson y probablemente sabía que una de las ideas más popu-

${ }^{28}$ Se le da aquí un sentido técnico a la palabra ejemplo, en tanto que equivalente retórico de la inducción, así como el entimema lo es del silogismo.

29 "Ridentia floribus arva", en ibid., libro I, v. 203.

30 "La orilla cercana, envidiosa, se duele de estas riquezas del campo flotante, y de este cultivo, y para competir, se adorna a sí misma con verdes olmos, cerezos, fecundos perales, rojizos manzanos, laureles, pinos, cedros y altas encinas, y con campos de primavera perenne" (ibid., libro I, vv. 205-209). 
lares en los círculos intelectuales europeos era la del silencio de las aves, que simbólicamente se asociaba con la falta de poetas de calidad en el Nuevo Mundo. Con todo este razonamiento, uno no puede sino sentirse tentado a relacionar con lo anterior la aparición de los poetas novohispanos a orillas del lago en el mismo libro, e incluso la Rusticatio completa en tanto que obra poética. Así, no sólo no hay silencio en las aves, sino que tampoco es verdad la supuesta impotencia expresiva de los escritores americanos. La mayor prueba que aporta la obra es, podría decirse, ella misma.

La mención sucesiva de los escritores de renombre parece implicar que, si Robertson y otros podían pensar eso, era simplemente por desconocimiento. Se levanta ante el grupo detractor, pues, la barrera epistemológica ya mencionada: no se trata sólo de que haya cosas inexplicables en la naturaleza, sino también que las nuevas visiones generadas por ellos no contemplan todos los hechos, ya sea por ignorancia o por lejanía. La identidad, pues, en este plano discursivo se muestra como un reclamo del derecho a definirse a sí mismo; o mejor dicho, una forma de negarse a ser contemplado como un objeto de curiosidad sin la capacidad de hablar de sí mismo.

Por otra parte, regresando al ejemplo argumentativo que representan las chinampas, dentro de éste se encuentra condensada una generalización diferente que no se ha mencionado y que es crucial en la argumentación. Dentro del relato acerca de la forma que comenzaron a construirse las chinampas, se describe así la reacción de los habitantes ante la exigencia de tributos muy altos por parte del rey de Azcapotzalco:

Ingemuere omnes, gemituque augusta replebant templa Deum: sparsis bacchatur turba capillis, omnia sed prudens vincit sollertia gentis. ${ }^{31}$

La astucia del pueblo se resalta como aquello que lo ayuda a vencer al tirano. Cabe recordar, al respecto, que era popular en la Europa del siglo XVIII la idea de que los "salvajes" -incluso en la visión de Rousseau-carecían de memoria, imaginación y raciocinio; la imagen del indio desmemoriado e incapaz de planificar llegó incluso a retratar a los habitantes de las Antillas como gente que vendía por la mañana su lecho de algodón y por la noche se daba cuenta de que tenía que comprarlo de nuevo porque no había podido prever que lo necesitaría después. ${ }^{32}$ Los considerados "grupos más avanzados" ocu-

31 "Se lamentaban todos y llenaban los sagrados templos de los dioses con gemidos: corre desaforadamente la turba con los cabellos enmarañados, pero todo lo vence la prudente astucia de la gente" (ibid., libro I, vv. 154-156).

${ }^{32}$ J. Cañizares Esguerra, op. cit., p. 195. 
paban un lugar intermedio entre esta falta absoluta de previsión y los grupos plenamente "civilizados".

Así, conjuntar al inicio del libro la idea de una naturaleza fértil y de un colono habilidoso y astuto puede verse como un doble ataque a la tesis de la inferioridad telúrica y humana de América. Pero no son sólo estos dos puntos, también los animales y muchas cosas más quedan englobados a lo largo del poema en la idea de fertilidad. Así, se comienza a perfilar la conclusión que se deriva de las dos premisas: el carácter productivo del continente se refiere tanto a la tierra como a todos los elementos que se desarrollan en su seno.

Sin embargo, falta mencionar un aspecto de gran importancia: en cierto modo se ajusta la idea del determinismo climático, parece criticarse su unilateralidad al plantear una relación recíproca. La influencia no ocurre sólo de la naturaleza al hombre, sino también de éste a aquélla; él también puede controlarla. Se trata, en efecto, de una temática tan evidente en Rusticatio mexicana que no hacen falta ejemplos para demostrarla. La fertilidad es, entonces, en muchos casos un resultado de la acción humana.

Esta conjunción hombre-naturaleza es la clave para llegar a la conclusión con que se hace la defensa ante las tesis acerca de la inferioridad del Nuevo Mundo: demostrar que el hombre en América es capaz de dominar la tierra y los animales para extraer de ellos diferentes beneficios equivale a insertar al americano en el plano general de la actividad humana, lugar que parecía negársele con la tesis de la inferioridad. El grupo detractor retrataba al americano en una fase estancada, como si éste sólo fuera una curiosidad atrapada en el tiempo, ${ }^{33}$ bastante valiosa para ellos, por cierto, para dar cuenta de los progresos del ser humano. Dicha inferioridad significaba carecer de las cualidades que se consideraban los rasgos específicos del hombre "civilizado", como la creatividad, la memoria, la previsión, el uso de ideas abstractas, la racionalidad, o incluso del ser humano, como la masculinidad en el caso del hombre, la capacidad de amamantar con leche saludable en el caso de la mujer.

Vale la pena recordar aquí el humanismo comercial de Robertson y, de un modo más general, el papel que tenía la existencia de grandes redes comerciales para que un pueblo pudiera considerarse "civilizado". La respuesta de Landívar a esto viene frecuentemente acompañada por una hipérbole. En un ejemplo donde también usa un polisíndeton, al hablar del tinte aportado por la grana cochinilla, se dice: "[colorem] quo Galli, et Batavi, Venetusque, Hispanus, et Anglus et Russi, et Belgae, totusque intingitur orbis". ${ }^{34}$

${ }^{33}$ No en vano las primeras palabras de De Pauw, en su libro más famoso, son éstas: "Les Américains forment le chapitre le plus curieux, et le moins connu de l'historie de l'homme" (C. De Pauw, op. cit., p. I).

34 "...color con el que se tiñen los franceses, holandeses, venecianos, hispanos, in- 
De un modo análogo pueden ser interpretados los prodigios, los cuales, en este segundo argumento, adquieren un sentido ligeramente diferente del que se describió anteriormente. Tómese como ejemplo el milagro del pocito de la virgen de Guadalupe. La presencia de la virgen emitiendo una señal que denota su paso por tierras novohispanas, un hecho natural palpable como un manantial, enlaza y crea una implicación mutua entre la naturaleza y la "verdadera" religión, haciendo que esta última le transfiera sus valores universales a la otra, que parecían serle sustraídos por las ideas detractoras. Así, este milagro y la aparición de las cruces también son parte de la lucha por lo universal, como un recurso apoyado en la tradición de los argumentos ya esgrimidos en el debate -piénsese en Antonio Ruiz de Montoya y la cruz de Carabuco en Perú. Los milagros son, en este sentido, un punto articulatorio, de enlace o conjunción entre la naturaleza, el hombre y, evidentemente, la religión católica.

Se percibe, entonces, que en el centro de la polémica está -en una continuidad sorprendente con la disputa de Sepúlveda y Las Casas- la idea de lo universal. Buffon, De Pauw y Robertson se la negaban al americano; Landívar, mediante este segundo argumento, trataba de devolvérsela, pero con dos matices principales: la idea de productividad como dominio sobre lo natural y la mención de fenómenos naturales cargados de simbología religiosa.

\section{Las estrategias retórico-argumentativas}

Hay diferentes tipos de argumentos y recursos retóricos en la Rusticatio que funcionan como los soportes de toda la reflexión anterior. Todos parecen confluir en ella.

Un primer elemento que hay que mencionar es un punto de encuentro entre el primer argumento frente al auditorio europeo y el que ahora se está analizando. En consonancia con la idea de lo inexplicable, además de los portentos, se despliega una temática a lo largo del poema que se basa en la oposición entre lo visible y lo oculto. Así, en una interesante nota al pie, ${ }^{35}$ después de una explicación muy precisa acerca de la elaboración del añil, se afirma que nadie puede saber a ciencia cierta qué tipo de añil saldrá del proceso. Se establece, así, un límite a la razón; tema que aparece frecuentemente en otros lugares y que ya ha sido aquí abordado. Pues bien, este mismo tema se engarza con la idea de fertilidad. He aquí un ejemplo del mismo libro:

gleses, rusos, belgas y todo el mundo" (R. Landívar, op. cit., libro IV, v. 185). Se puede apreciar lo mismo en los versos 183-184 del libro $\mathrm{V}$, donde el añil acrecienta negocios en todo el orbe.

${ }^{35}$ Ibid., libro v, v. 201. 
Quae videas nigris compacta medullis aequora, crede mihi, turgescunt ubere gleba nec meliora satis praestat natura ferendis. ${ }^{36}$

La riqueza de algo, entonces, no es necesariamente ostensible a primera vista, sino que se muestra en aquello que es capaz de producir. Así, en este claro argumento pragmático que valora algo en función de sus efectos, se puede observar cómo se entrelazan dos de las ideas principales del poema: por una parte, lo inexplicable y los límites de la razón; por otra, lo productivo.

Perelman menciona que, respecto al nexo causal en la argumentación, "es necesario subrayar las diferentes valoraciones que se producen al interpretar una relación causal como hecho-consecuencia, con un énfasis en el primero, o como medio-fin, realzando este último". ${ }^{37}$ Se puede percibir ahora cómo se articula el segundo argumento de Landívar en contra del grupo detractor: éste, en una clara tendencia especulativa, buscaba explicaciones para una multitud de datos, quería darles coherencia mediante el planteamiento de una sola causa, la inferioridad; Landívar, por su parte, resalta la imposibilidad de conocer todas las causas e invierte el esquema, transformándolo en una relación entre medio y fin. Lo siguiente dejará claro el énfasis en el fin:

Ipse coloratum credas subsidere caenum sordibus imbutum glaucis, ac fonte liquatum: hoc tamen ampla luto gazas Guatimala cogit ingentes, totusque auget commercia mundus. ${ }^{38}$

El poema de Landivar se presenta, en este caso, como un llamado a que la Nueva España sea juzgada a partir de aquello que puede producir, precisamente en un tiempo en que los resultados económicos de las reformas borbónicas ya se percibían en el auge de ciertos productos.

Esta diferencia entre la forma detractora de presentar el tema y la de Landívar se percibe en el hecho de que, aunque en casos específicos sus datos coinciden, llegan a lugares distintos. Por ejemplo, para De Pauw, lo que de-

36 "Los campos compactos que ves con negras entrañas, créeme, están hinchados de tierra fértil, y la naturaleza no proporciona mejores que éstos para las cosechas" (ibid., libro v, vv. 22-24). Véase también libro viI, vv. 33-34, donde es clara la idea de la riqueza oculta, en este caso en relación con las minas.

${ }^{37}$ C. Perelman y L. Olbrechts-Tyeca, op. cit., p. 417.

38 "Tú mismo creerás que un cieno teñido está asentado, impregnado de inmundicias verdes y revuelto con agua; pero de este lodo la amplia Guatemala saca enormes tesoros, y todo el mundo incrementa los negocios" (R. Landívar, op. cit., libro v, vv. 181-184). 
mostraba que había ocurrido una gran inundación en el Nuevo Mundo que había corrompido el desarrollo de la naturaleza y el hombre eran:

Los huesos fósiles de animales gigantescos (que pensó que habían sido los primeros en morir en el diluvio); grandes cuerpos de agua, tanto lagos como ríos; terremotos y volcanes activos que aún estremecían la tierra; conchas marinas esparcidas por valles bajos; metales preciosos sobresaliendo de la superficie de la tierra (que la primitiva sedimentación de la tierra debía de haber enterrado en lo profundo). ${ }^{39}$

No hace falta leer a fondo el poema de Landivar para darse cuenta de las coincidencias. Lo anterior hace necesario reajustar lo que se ha afirmado aquí en relación con la novedad con que la Rusticatio se presenta ante el auditorio europeo. Se llegó a la conclusión, en el primer argumento analizado, de que la premisa de fondo no eran los hechos sino la objetividad, puesto que en esta última se fundaba la posibilidad de presentar con coherencia cosas cuya característica central era la novedad, como los prodigios. En cambio, en el segundo argumento frente al auditorio europeo, para respaldar la idea del carácter productivo de la tierra sólo se podía recurrir, como premisa, a un hecho que no fuera punto de controversia: la humedad. Así pues, las coincidencias antes citadas no entran en contradicción con la importancia de la novedad y la atribución de cierto desconocimiento al auditorio europeo, se trata de argumentos diferentes; juntos, parecen afirmar que dicho auditorio no posee todos los hechos. De todo lo anterior se deduce que el reajuste que es preciso hacer es una ampliación de la premisa de la humedad: no es sólo la supuesta gran cantidad de agua, sino también las correspondencias antes mencionadas entre De Pauw y Landívar.

En efecto, se parte de todas ellas del mismo modo ya descrito respecto al agua. Se dijo que lo esencial es que de ésta se hace derivar la fertilidad, lo productivo; pues bien, se llega exactamente a la misma conclusión con las conchas marinas - la púrpura y la producción de la tinta-, los metales e incluso los volcanes - a la larga, las erupciones generaron una purificación de la tierra y el aire. El procedimiento es el mismo: oscurecer la causa y magnificar el fin.

Una vez descrita la forma en que se argumenta la fertilidad, hay que explicar cómo se da la transición entre ésta y la lucha por lo universal mencionada anteriormente. Dicha transición puede dividirse en dos fases: una caracterizada por el uso del ejemplo, lo inductivo y, por tanto, la progresiva generalización; y otra que se basa en lo que se podría ver como un entimema, fundándose en lo deductivo.

${ }^{39}$ J. Cañizares Esguerra, op. cit., p. 89. 
Respecto a la primera etapa, el papel del ejemplo ya fue analizado al mencionar las chinampas y la formación de la idea de lo productivo. Además de esto, el argumento más utilizado es el de transitividad. Por ejemplo, al inicio del libro dedicado a los ganados menores ${ }^{40}$ se presenta una descripción de los campos destinados a la ganadería, lo cual se engarza con todas las partes anteriores de la obra dedicadas solamente a parajes naturales. En este caso, hablar primero del verdor de los campos es un preludio al tema de la prosperidad del ganado. Es, pues, un desarrollo de los temas anteriores. Si hay clima y naturaleza favorables, entonces los ganados pueden criarse sin problemas; es así como comienza a alternarse en la descripción la abundancia del campo con el desarrollo de los animales. ${ }^{41}$ Podría verse aquí una relación causa-efecto; sin embargo, se trata más bien de un argumento de transitividad. No se enfatiza el nexo temporal, sino algo de carácter lógico: los ganados y muchos otros elementos quedan subsumidos por la categoría más general llamada naturaleza, cuya productividad ya se intentó demostrar en la obra. En este ámbito, sin duda, la idea del determinismo climático es favorable y permite generalizar la fertilidad a una multitud de hechos distintos: la fecundidad de los animales, resaltando por supuesto los "bríos" amorosos de los animales y sus hábitos de reproducción, ${ }^{42}$ la facilidad del cultivo del nopal, que tanto en campos fértiles como miserables crece sin dificultad, ${ }^{43}$ etcétera.

Cabe destacar que en algunos casos -que, vistos en el panorama general de la obra, son minoría- sí hay una visión de la adversidad de la naturaleza como destrucción. En el apartado anterior, esto fue descrito como parte del propósito de resaltar lo singular, englobando tanto lo favorable como lo temible; sin embargo, desde el punto de vista de la defensa de la productividad de la Nueva España, las menciones aisladas de esto crea una idea de imparcialidad. Este aspecto aparece desde el primer libro, y es así como se describe una parte del lago de Texcoco:

Aequora quin etiam salso foedata sapore

flumineos propiis pisces a fluctibus arcent.

Quod siquem dulcis pertaesum Chalcidis ardor caecus agat salsam nando penetrare paludem, pestiferas ut tangit aquas, leto occidit atro. ${ }^{44}$

${ }^{40}$ R. Landívar, op. cit., libro XI, vv. 25-32.

${ }^{41}$ Ibid., libro XI, vv. 283-285.

${ }^{42}$ Ibid., libro X, vv. 146-147.

43 Ibid., libro IV, v. 50.

44 "Más aún, las aguas del lago, enturbiadas por un sabor salado, alejan a los peces fluviales de sus propias corrientes; pues si a alguno, hastiado del dulce lago de Chalco, 
La hipérbole final que alude a la instantánea muerte al tocar el lago es parte de la idea de lo admirable, pero la imagen de un lago insalubre que hunde en la putrefacción todo lo que lo rodea es un tipo de concesión que, en realidad, por su carácter específico desmiente la perspectiva global desde la cual América era descrita como un lugar malsano (De Pauw).

Teniendo en cuenta los aspectos mencionados - la generalización de la fertilidad mediante el ejemplo y la transitividad, por un lado; la manifestación de imparcialidad a través de la concesión, por el otro-, se puede comprender cómo se da la transición entre lo que podría verse como dos modalidades descriptivas, dos caras de una misma moneda: algo es exaltado por su valor único y singular, y simultáneamente es circunscrito en un ámbito global -que se presenta como total, completo- con el que comparte significados. La parte le transfiere valores al todo, y viceversa.

Una característica del poema en la que es particularmente evidente este proceso es la gran cantidad de entrecruzamientos temáticos en los diferentes libros. Al ver de un modo general los temas principales de la obra y la forma en que están articulados, lo primero que salta a la vista -algo que ya subrayaron Higgins y Rodríguez Gil- ${ }^{45}$ es la ruptura que representa el libro IV: los tres primeros parecen estar enteramente dedicados a los parajes naturales, mientras que el tema del dominio del hombre sobre la naturaleza se manifiesta a partir del libro IV y se desarrolla hasta el libro $\mathrm{XI}^{46}$-con la pequeña interrupción del libro VI, referente a los castores, en cuyo contenido, no obstante, está presente la idea del hombre, tanto por las humanizaciones como por la idea de la utopía ya señalada por Kerson. ${ }^{47}$ Sin embargo, esta visión se sostiene sólo al hacer caso omiso de una multitud de elementos o detalles que aparecen a lo largo de los libros y al contemplarlos principalmente a partir de sus títulos. Esto es sin duda lo que ha llevado a otros analistas a afirmar que no hay orden alguno perceptible. En realidad, si hay una estructura en la obra que le da coherencia desde el punto de vista temático, ésta no puede ser otra que la provocada por la interrelación y escalonamiento de las dos modalidades descriptivas; no una

lo fuerza su ciega ambición a penetrar a nado el salobre pantano, en cuanto toca sus aguas venenosas sufre una horrible muerte" (ibid., libro I, vv. 314-318).

${ }^{45} \mathrm{G}$. S. Rodríguez Gil, La Rusticatio mexicana en el ambiente literario del siglo XVIII. Ensayo histórico cultural. México, Universidad Iberoamericana, 1954.

${ }^{46}$ Higgins afirma que los tres primeros libros se concentran en la geografía, los ocho subsecuentes en las áreas clave de la producción económica del virreinato, y los otros en asuntos varios que no entran en el ámbito de actividades productivas (A. Higgins, op. cit., p. 119); Rodríguez Gil ya había hecho la misma división de la obra, otorgándole al primer bloque el carácter de descriptivo, al segundo el de didáctico, y, al último, una vez más el de descriptivo (G. S. Rodríguez Gil, op. cit., p. 50).

${ }^{47}$ A. L. Kerson, "The Republic of the Beavers", en op. cit. 
línea recta, sino más bien un espiral, un círculo cuyos patrones se repiten a pequeña y a gran escala.

Por ejemplo, se puede afirmar sin temor a equivocarse que el libro I de Rusticatio mexicana condensa dentro de sí la mayor parte de los temas que después serán desarrollados: la fertilidad, la conjunción hombre-naturaleza desde el punto de vista de la agricultura (las chinampas), lo temible (el lago de Texcoco), las aves y sus cantos, la cruz en el fondo del lago como prodigio, e incluso la caza y los juegos (condensados en la descripción de la pesca); algo parecido se puede decir del apéndice. Algo similar se puede encontrar en el libro II, donde aparecen elementos anteriores, como el agua y otros pájaros. Todo esto apunta a un tipo de conformación descriptiva de la totalidad de la naturaleza, conformación basada en el entrelazamiento de diversos aspectos que hacen del reino natural novohispano uno solo; cada entrecruce temático encuentra su pertinencia en una relación de la parte al todo. Una nueva singularidad ensancha el diámetro de la totalidad.

En respaldo de la noción de totalidad se despliegan tanto figuras retóricas como recursos que entrarían en el terreno de la dispositio. Sin duda, el uso continuo de la transitio refuerza la cohesión de la obra y contribuye a la totalidad; lo mismo ocurre con las frecuentes recapitulaciones y los pequeños resúmenes que se hacen por adelantado.

La idea de un todo indisoluble donde cada elemento está imbricado con los otros es, en realidad, algo respecto a lo cual parece haber un acuerdo generalizado en relación con la Rusticatio; algunos lo llaman "proyecto de representación totalizadora". ${ }^{48}$ Pero hay que observar que esto radica en el modo de la obra de presentarse a sí misma creando la imagen de algo completo, por medio del ejemplo, la transitividad y la concesión antes mencionados. Esto sólo es parte de la primera fase del argumento para llegar a la lucha por lo universal.

Por último, respecto a dicha fase, hay que recalcar que con el acto de presentar una totalidad está inextricablemente unido el de hacer omisiones; hay silencios significativos en Rusticatio mexicana, como se puede notar en el hecho de que, al abordar el tema del trabajo en las minas y acercarse a las condiciones deplorables de los trabajadores, sólo se emita la siguiente interrogación: "Quid vero non cogat opum vesana cupido?" 49

En esto, de gran importancia, hay que subrayar el hecho de que se le atribuyan completamente las pésimas condiciones de trabajo a la codicia humana

${ }^{48}$ Marcela Alejandra Suárez, "Los prodigia de la cruz: Identidad y memoria en la Rusticatio mexicana", en Bibliographica Americana, núm. 3, abril, 2006, p. 3.

49 "¿A qué no obliga, en efecto, el deseo frenético de riquezas?" (R. Landívar, op. cit., libro VII, v. 86). 
en general con un tinte condenatorio desde el punto de vista católico (sin saber exactamente si se refiere a la codicia de los trabajadores o a la de los jefes de la clase dominante), pasaje donde es manifiesto el silencio que parece haber detrás de la pregunta de Landívar, al pasar por alto las condiciones sociales específicas (la organización estamental, las castas, el hecho de que no podía de ninguna manera ser un criollo o un español el que laborara en ese lugar) en que una persona podía verse arrastrada a un trabajo semejante. Lo importante en esto es que la mención de algo de manera enfática está frecuentemente acompañada por la omisión de otro aspecto, lo cual no es sino el componente específicamente argumentativo de las figuras de elección: escoger algo frente a diversas opciones posibles. Con totalidad, por lo tanto, se hace referencia aquí a un rasgo discursivo-argumentativo, un modo de presentar un conjunto de elementos, y no algo de carácter ontológico, como si efectivamente se hiciera un catálogo completo de lo productivo en la Nueva España.

Una vez analizada la primera fase del argumento, la generalización de lo productivo, falta mencionar la segunda, un entimema, ${ }^{50}$ el cual conduce a la conclusión. Desde el punto de vista de la productividad y de la conjunción hombre-naturaleza, la estructura de dicho entimema se puede postular como sigue: $a$ ) una de las características de la actividad humana es la producción o extracción de bienes a partir de la naturaleza; $b$ ) el habitante novohispano lo hace; y c) por lo tanto, el novohispano es como cualquier hombre, es decir, no inferior. En última instancia, afirmar que la tierra novohispana es capaz de producir diversas cosas equivale a otorgarle una de las características que se pueden considerar propias de cualquier tierra; del mismo modo, decir que el hombre novohispano puede ejercer dominio en ella es insertarlo en el plano de la actividad humana, que comparten todos los hombres.

El mismo entimema, con idéntica conclusión, puede ser planteado a partir de los prodigios con simbolismo religioso, los cuales, en tanto que señales del mundo redimido en la naturaleza novohispana, incorporan a esta última en el devenir del cristianismo y, por tanto, de la humanidad. Éstos, aunque se apoyan en una tradición específica, tienen una diferencia leve con respecto a ella; anteriormente era más normal enmarcar esto en un plano histórico (nexo de sucesión), ya sea poniendo a los americanos como descendientes de una de las tribus perdidas de Israel o conectando al apóstol Tomás con Quetzalcóatl, pero Landívar lo ubica en un ámbito distinto: la naturaleza; sumamente conveniente, por cierto, para hacer frente a las ideas del grupo detractor. Es así como se explica el hecho de que, respecto a uno de los grandes símbolos religiosos

${ }^{50}$ Recuérdese que los entimemas son silogismos cuyas premisas son opiniones generalmente admitidas que a veces no hace falta mencionar. 
criollos, la virgen de Guadalupe, no tenga cabida la historia de su aparición a Juan Diego en la Rusticatio, sino su manifestación como un fenómeno natural y milagroso: el pocito. Hay que recordar que, de manera particular en relación con la virgen de Guadalupe, los fundamentos históricos del milagro eran el problema central tanto para los defensores criollos como para sus adversarios, ${ }^{51}$ que ya eran numerosos en el siglo XVIII. Las defensas más normales del milagro se concentraban en el aspecto historiográfico, puesto que alcanzar pruebas en este ámbito era demostrar sin equívocos que en efecto había ocurrido. Así pues, no se puede ver sólo una pertinencia temática en el hecho de que en la Rusticatio se presentara solamente una versión natural del milagro, sino también una intención de dar un anclaje objetivo de lo que podía hacer la Guadalupe. Hacerla patente en la naturaleza era un esfuerzo por validarla.

Respecto a los prodigios milagrosos, se puede plantear la presencia de un argumento basado en un nexo de coexistencia entre el símbolo y lo simbolizado. ${ }^{52}$ Hay una transferencia de valores entre el símbolo de la cruz y el lugar en que se encuentra, la Nueva España, del mismo modo antes descrito entre la parte y el todo. Con esto, el énfasis en la naturaleza plantea una relación de carácter atemporal, ya no histórica, como en los otros casos.

Rusticatio mexicana, por consiguiente, describe un conjunto estático e inamovible en el tiempo. Si se recuerdan las tesis del grupo detractor, se podrá ver que, si ellos son capaces de hablar de inferioridad, es porque están pensando en términos de diferencias en una escala de desarrollo humano a lo largo del tiempo. Pero Landívar se opone a la idea en un plano enteramente distinto, se podría decir que cambia el terreno de la disputa para poder hacer frente a las perspectivas diacrónicas, pues en estas últimas se fundaba la posibilidad de hablar de algo inferior o retrasado. La universalidad -el estatus de civilizado- a la que se quiere adscribir la Nueva España es atemporal.

A lo largo de este artículo se han expuesto los resultados a los que se ha llegado al analizar la obra al trasluz de la disputa del Nuevo Mundo. El presupuesto ha sido que la identidad es ante todo discursiva, y en tanto tal, se inserta en un diálogo y en él se construye. Se vio, en un primer paso, que el sentido que tienen lo admirable y lo singular es el de una barrera que plantea los límites del conocimiento. En este ámbito, se trata de un doble movimiento que consiste en descubrir y encubrir al mismo tiempo; se ponen de manifiesto cosas novedosas, proporcionando las causas de algunas e incluso discutiéndolas en algunos pasajes, y dejando otras en el ámbito de lo inexplicable. En un

${ }^{51}$ Iván Escamilla González, “'Máquinas troyanas': El guadalupanismo y la Ilustración novohispana”, en Relaciones, vol. 21, núm. 82. Zamora, Michoacán, El Colegio de Michoacán, primavera, 2000, p. 219.

${ }^{52}$ C. Perelman y L. Olbrechts-Tyeca, op. cit., p. 509. 
segundo momento, se describió la forma en que la idea de lo productivo amplía su rango de acción y sirve como punto de apoyo para librar la lucha por lo universal. Es precisamente esta universalidad lo que subyace a la búsqueda de singularidad en Rusticatio mexicana. La "exaltación de lo propio", por tanto, es sólo el vértice más visible de un conjunto de cimientos con mayores posibilidades semánticas, simbólicas, argumentativas. Queda clara, entonces, la transición entre los dos argumentos frente al auditorio europeo: lo singular conduce a lo universal. 